TI 2012-117/VIII

Tinbergen Institute Discussion Paper

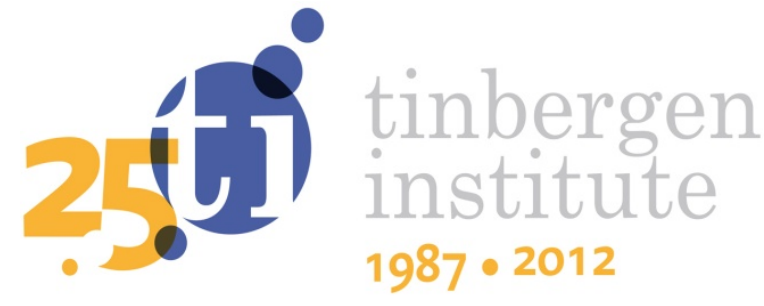

\title{
Advantaged Bidders in Franchise Auctions
}

Vincent A.C. van den Berg

Faculty of Economics and Business Administration, VU University Amsterdam, and Tinbergen Institute. 
Tinbergen Institute is the graduate school and research institute in economics of Erasmus University Rotterdam, the University of Amsterdam and VU University Amsterdam.

More TI discussion papers can be downloaded at http://www.tinbergen.nl

Tinbergen Institute has two locations:

Tinbergen Institute Amsterdam

Gustav Mahlerplein 117

1082 MS Amsterdam

The Netherlands

Tel.: +31(0)205251600

Tinbergen Institute Rotterdam

Burg. Oudlaan 50

3062 PA Rotterdam

The Netherlands

Tel.: +31(0)10 4088900

Fax: $+31(0) 104089031$

Duisenberg school of finance is a collaboration of the Dutch financial sector and universities, with the ambition to support innovative research and offer top quality academic education in core areas of finance.

DSF research papers can be downloaded at: http://www.dsf.nl/

Duisenberg school of finance

Gustav Mahlerplein 117

1082 MS Amsterdam

The Netherlands

Tel.: +31(0)20 5258579 


\title{
Advantaged bidders in franchise auctions
}

\author{
Version of 26 October 2012 \\ Vincent A.C. van den Berg* \\ Department of Spatial Economics \\ VU University Amsterdam \\ De Boelelaan 1105 \\ $1081 \mathrm{HV}$, Amsterdam, The Netherlands \\ v.a.c.vanden.berg@vu.nl
}

\begin{abstract}
Consider a government that auctions a franchise for, e.g., an airport, telecommunication network, or utility. Consider an "incumbent bidder" that owns a complement or substitute. With an auction on the transfer (i.e. payment) to the government, the incumbent is advantaged. If the government regulates the market with an auction on the price asked to consumers, it depends who is advantaged. With complements, the incumbent is advantaged: it can set a lower price on the new franchise, as this increases the profit of the other. With substitutes, the incumbent is disadvantaged. In many settings, the advantage bidder always wins.
\end{abstract}

\section{Acknowledgements}

Financial support from the ERC (AdG Grant \#246969 OPTION) is gratefully acknowledged. I am grateful for the comments of Harry van der Weijde, Sergej Gubins, Paul Koster, Alex Dimitropoulos, Hugo Silva and Eva Gutiérrez. I thank the participants of the Eureka seminar (13 September 2012, Amsterdam). The usual disclaimer applies.

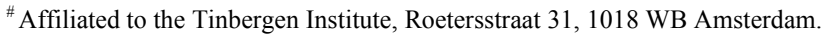




\section{Introduction}

How is an auction affected if one bidder owns a complement or substitute to what is auctioned? Such a bidder will be referred to as an "incumbent"; the other bidders are "new bidders". This issue may, for instance, occur when the government auctions a franchise for the right to operate a telecommunication network, a utility (e.g. water supply or waste disposal), an airport, a public-transport or airwave frequencies. When auctioning off an airport, one bidder could own another airport in the region, an airport that is frequent destination, or a competing high-speed rail link. When auctioning broadband internet frequencies, some bidders could own complementary frequencies for telephoning or broadband frequencies in a nearby area. With an auction for the franchise for electricity supply (to households), a bidder might already supply the natural gas in that region.

Similarly, in a takeover battle of a firm, a competitor or a supplier might be willing to offer a premium, as taking over the firm betters its market position. In procurement, a firm that won before might have developed expertise or a firm that is currently working on many projects might have difficulty starting a new one.

For ease of reference, this paper focuses on the case where the government auctions a franchise for a facility (also referred to as tendering), but the analysis has broader implications. The focus is on second-offer auctions with 2 bidders, where the winner has to (at least) match the bid of the loser. There are two facilities that are imperfect substitutes or complements. One facility is auctioned, and one bidder owns the other facility. The value of owning the new facility to a firm is modelled in two distinct ways. In the first "private-value" setting, firms differ in the value, as they have different marginal costs. In the second "common-value" setting, the marginal cost will be the same for both bidders, but they have different expectations, and update these when they learn the other's expectation. ${ }^{1}$ This paper extends the literature by explicitly modelling the effect of advantages in franchise auctions, and most importantly by analysing the regulatory "price auction" (where bidders compete on the price they ask consumers) and not only a "transfer auction" (which has a standard scoring rule where bidders compete on how much they transfer (i.e. pay to or receive from) to the government).

In a transfer auction, for given (expectations of) demand and costs functions, the incumbent is willing to pay a higher transfer than a new bidder: if it wins, it has a monopoly on the two facilities; if it loses, there is a duopoly, and profits of both facilities are lower. With privatevalues, the incumbent is advantaged and wins more often. If there is little heterogeneity (in the marginal costs of the bidders) or the facilities are strong substitutes or complements, the incumbent always wins, as the advantage is then so large that the new firm can never win.

These results are in broad accordance with the literature. Burkart (1995) investigates a takeover battle of a firm where one bidder owns part of it (i.e. has a toehold) using a secondprice auction and private-values. The toehold bidder has the advantage and bids more

\footnotetext{
${ }^{1}$ The firms could alternatively differ on (the expectance on) the demand function. The results of this paper would generally transfer to this setting (see Section 6 for a discussion).
} 
aggressively. This in turn raises the expected revenue for the other shareholders, but leaves the other bidder worse off. Krishna and Rosenthal (1996) study radio-frequency auctions for multiple regions with local and global bidders, where the latter are advantaged because of synergies if they win in multiple regions.

A transfer auction only raises revenue. As Hazlett and Muñoz (2009) also argue, a welfaremaximising government should also care about consumer surplus and fostering competition. This could be done by attracting more firms to the market. But, alternatively, the government could use an auction on the price that will be set, ${ }^{2}$ where the lowest offered price wins, to regulate the market. The advantage of regulation via an auction over direct regulation is that the government needs less information on the demand and cost conditions (Verhoef, 2007).

With a perfectly competitive auction in Verhoef (2007), a price auction leads to the firstbest outcome: marginal-cost pricing. Van den Berg (2012) extends this analysis to when two facilities are auctioned. The price auction is robust: it attains the first-best regardless of whether the facilities are complements or substitutes, and of whether the facilities are auctioned off to a single firm or to two firms. Conversely, a transfer auction never attains the first-best, and its effects are sensitive to these considerations. ${ }^{3}$ With imperfect competition, a price auction generally does not result in marginal-cost pricing; but the price does approach the winner's marginal cost as the auction becomes more competitive.

A price auction is also affected if there is an incumbent. Interestingly, this paper finds that it depends on the setting which bidder has the advantage: with substitutes the new bidder is advantaged, with complements the incumbent. Under private-values, a new firm offers a price equal to its marginal cost. With complements, the incumbent has the advantage: it is willing to offer a price below its marginal cost, as this is compensated by that, if it loses, the new firm will have to set a lower price, and this raises the profit from the other facility. This offering of a lower price also increases the welfare gain of this regulatory auction. Conversely, with substitutes, the incumbent is at the disadvantage: it wants a higher price on the new franchise to increase the profit from the other. Accordingly, the expected prices are higher than with two new firms, and welfare tends to be lower.

The common-values setting gives a more extreme outcome than private-values. Now, this paper finds that the advantaged bidder always wins (even if it has the lowest signal and the other the highest) and for any parameterisation. ${ }^{4}$

Similarly, Klemperer (1998)—who studies common-values where one bidder has a tiny extra value - also finds that the advantaged bidder always wins. Bulow et al. (1999) extend this

${ }^{2}$ Alternatively, they could compete on the number of users, which is equivalent in our setting (see also Verhoef, 2007).

${ }^{3}$ Perfect competition seems unlikely in an auction: in reality, costs and demands do vary over firms (Gómez-Ibáñez and Meyer, 1993) and

there seems to be substantial uncertainty (Flyvbjerg et al., 2003, 2007). Moreover, there are often a limited number of bidders.

${ }^{4}$ This result can be illustrated by the case where the value of winning is just the sum of the two signals, but the advantaged firm has a tiny extra value $\alpha>0$. The disadvantaged firm $d$ with signal $t_{d}$ is willing to pay $t_{a}+t_{d}$ (note that it does not know $t_{a}$, but it does have a belief about it), whereas the other is willing to pay $t_{a}+t_{d}+\alpha$. Suppose the disadvantaged followed the same strategy as without advantages and bids twice its signal: $t_{d}+t_{d}$. If it would then win, this would be very bad news: then the advantaged signal must follow $t_{a} \leq t_{d}-\alpha / 2$, and thus the value for the disadvantaged is not above $t_{a}+t_{d} \subset \alpha / 2$, which is below the bid. Hence, whenever it wins, it makes a loss. To overcome this, the disadvantaged shades its bid. But knowing this, the advantaged can bid more aggressively, which in turn implies that the disadvantaged must shade its bid even more, and so on until the disadvantaged always bids as if the advantaged's signal is zero (or does not bid at all if, for example, there are bidding costs). Hence, the disadvantaged never wins, and the advantaged wins at a low price. 
to a takeover battle with common-values and both bidders having a toehold. The bidder with the larger toehold is advantaged, but does not always win. They also study a first-price auction, and find that it often improves the outcome for the auctioneer.

A final result of this paper is that the structure of the advantages is the same with commonvalues and private-values: the incumbent always wins the transfer auction and the price auction with complements, the new firm always wins the price auction with substitutes. In reality, there will be a mix of common- and private-values, but the share that is common is probably large. Hence, it is important to consider whether there are incumbent bidders, and how large an advantage or disadvantage they have.

Advantages also occur in other settings: for instance, takeover battles with toeholds (Burkart, 1995; Bulow et al., 1999); and, when bidding for franchises, a firm can be advantaged by having information on potential customers or a well known brand-name (Klemperer, 1998). ${ }^{5}$

Also in procurement auction, advantages can be important. McAfee and McMillan (1989) study procurement when there are two types of bidders, domestic and foreign, who differ in the distribution they draw their values from. It may be optimal for the government to discriminate between types - and hence not necessarily buy from the cheapest firm - because this intensifies the competition in the auction.

McAfee and McMillan (1989) only focus on costs, but other factors may also be important: such as quality or timeliness of delivery. Che (1993) assumes private-values and investigates how to score quality and price: the optimal rule under-valuates quality to limit the rents of relatively efficient firms. Branco (1997) investigates this question when bidders have correlated values (i.e. a mix of common- and private-values). Finally, Asker and Cantillon (2010) analyse what happens when firms differ in two dimensions - fixed cost and cost of quality - and compare the outcome of different types of auctions and of direct negotiation.

The next section introduces the model. Section 3 studies auctions with two new bidders. Sections 4 and 5 turn to auctions with an incumbent and new bidder for, respectively, privateand common-values. Section 6 discusses some caveats to the research. Section 7 concludes.

\section{General set-up}

The two facilities are imperfect substitutes or complements. Facility $A$ is auctioned off; the incumbent owns facility $B$. The number of users of $A$ is $q_{A}$; its price is $p_{A}$; and demand and inverse demands for $A$, respectively, follow (and likewise for $B$ ) ${ }^{6}$

$$
\begin{aligned}
& q_{A}=b_{0}-b_{1} \cdot p_{A}+b_{2} \cdot p_{B}, \\
& p_{A}=d_{0}-d_{1} \cdot q_{A}+d_{2} \cdot q_{B} .
\end{aligned}
$$

\footnotetext{
${ }^{5}$ Other examples include: dissolution of a partnership (Cramton et al., 1987), creditors bidding in bankruptcy auctions (Burkart, 1995), heirs bidding for a family estate (Engelbrecht-Wiggans, 1994), and charity auctions (Goeree et al., 2005). In all these settings, some or all bidders receive a share of (the utility from) the winning offer.

${ }^{6}$ Here, $b_{0}=d_{0} /\left(d_{1}+d_{2}\right)>0, b_{1}=d_{1} /\left(d_{1} \cdot d_{1}-d_{2} \cdot d_{2}\right)>0$ and $b_{2}=-d_{2} /\left(d_{1} \cdot d_{1}-d_{2} \cdot d_{2}\right)$, and following standard micro $d_{1} \cdot d_{1}>d_{2} \cdot d_{2}$ (Mas-Colell et al., 1995).
} 
Demand decreases with the own price, and hence $d_{1}, b_{1}>0$. For substitutes, demand increases with the other's price, and thus $b_{2}>0$ and $d_{2}<0$; the opposite holds for complements. Assuming away income effects, consumer surplus is the line-integral of the two demands. Welfare is the sum of consumer surplus and profits (including the transfer), and thus the value of a dollar of revenue for the government is assumed to be one dollar and taxation is costless. The assumption of linear demand is not crucial to the results; it only simplifies the exposition.

In the duopoly, firms maximise their profit given the other's price. Because the facilities are not perfect substitutes, the firms make a profit even though they compete on prices. The marginal cost of $A$ for bidder $k$ is $m c_{k, A}$. On $B$, marginal cost is $m c_{B ;}$. The price of firm $k$ on facility $A$, given the price on $B$, can be shown to be (and similarly for $B$ )

$$
p_{k, A}^{*}=\frac{b_{0}+b_{2} p_{B}+d_{1} \cdot m c_{k, A}}{2 d_{1}},
$$

Where superscript ${ }^{*}$ indicates the duopoly, while ${ }^{* *}$ will indicate a monopoly. The Nashequilibrium prices, and thus profits, are easily obtained from this equation.

If the incumbent controls $A$ and $B$, we have a monopoly, and the price equation is

$$
p_{I, A}=\frac{b_{0}+b_{2} p_{B}+d_{1} \cdot m c_{I, A}+b_{2}\left(p_{B}-m c_{B}\right)}{2 d_{1}} .
$$

With substitutes $b_{2}>0$, and hence the monopolistic prices are higher than the duopolistic ones. Conversely, with complements $b_{2}<0$, a duopoly leads to even higher prices than a monopoly since a lower competitor's price induces a higher own price. In all cases, except with independent markets $\left(b_{2}=0\right)$ or when the price of $A$ is forced to equal the marginal cost (due to regulation or an auction), the incumbent increases its profits from $B$ if it wins $A$.

Under the duopoly, the equilibrium prices are higher the higher the cross-price parameter $b_{2}$ is. Indeed with complements, as for example also discussed by Economides and Salop (1992), the prices are actually higher than with a monopoly, since a duopolistic firm ignores that its mark-ups lower the profit of the other.

The signal of both bidders is drawn from the same distribution that ranges between zero and one. The distribution function is $F[t]$, the density function $f[t] \equiv \partial F[t] / \partial t$. This paper considers common- and private-value settings. With private-values, the marginal cost on $A$ decreases with the bidders signal, $t_{k}$, following

$$
m c_{A, k}^{p}\left[t_{k}\right]=m c_{\max }^{p}-r \cdot t_{k}
$$

where superscript ${ }^{p}$ indicates private-values, $m c_{\max }^{p}$ is the maximum marginal cost with privatevalues, and $r$ a positive parameter. Similarly, with common-values, the marginal cost linearly decreases in the signals of bidders $k$ and $j$ :

$$
m c_{A, k}^{c}\left[t_{k}+t_{j}\right]=m c_{\max }^{c}-\frac{r}{2}\left(t_{k}+t_{j}\right)
$$


where superscript ${ }^{c}$ indicates common-values. The paper considers second-offer auctions, where the winner should at least match the loser's offer. With two bidders, the ascending and sealed-bid versions of this auction are equivalent, so this distinction will be ignored. When a tie occurs, the winner is determined by a coin flip; but, with the used continuous distribution of signals, this occurs with zero probability. It is assumed that the bid functions are continuous, and that if there are two new bidders the symmetric equilibrium results.

\section{Bidding without advantages}

To understand the effects of advantages, one first needs to understand the outcome without them. Hence, this section analyses two new bidders competing for $A$, whereas the incumbent owns $B$ and sets the duopolistic price following (2). ${ }^{7}$ In general, with a second-offer auction without advantages, a bidder offers its value (Burkart, 1995; Klemperer, 1998), and at that offer makes a zero profit.

We will start with the bidding strategies with common-values; those with private values will follow naturally from these. In a transfer auction, the duopolistic profit from $A$ for bidder $k$ ( $\left.\Pi_{A}^{*}\left[t_{k}, t_{j}\right]\right)$ increases in both signals. Assuming that the bidding strategies are the same for the two, it is optimal for $k$ to offer to transfer its entire profit when $t_{j}=t_{k}$ :

$$
T_{k}^{c}\left[t_{k}\right]=\Pi_{A}^{*}\left[t_{k}, t_{k}\right]
$$

where superscript ${ }^{\mathrm{c}}$ indicates common-values and ${ }^{*}$ a duopolistic market. $\Pi_{A}^{*} p_{A, k}^{N E}$ is the Nashequilibrium price of $A$, and $q_{A}^{N E}$ the corresponding demand. Suppose $k$ offered a slightly higher transfer instead: nothing changes if it won before and still wins (it still pays $j$ 's offer) or if $k$ still loses (it still has zero profit); but, if $k$ lost before and now wins, the transfer must be higher than the profit and $k$ attains a negative pay-off. Symmetrically, if $k$ would bid lower, it would be worse off if it just won the auction before, and now loses it.

Similarly, with a price auction, $k$ offers a price equal to marginal cost when $t_{j}=t_{k}$, such that it then makes a zero profit:

$$
p_{A, k}^{c}=m c_{A, k}^{c}\left[t_{k}+t_{k}\right]=m c_{\max }^{c}-\frac{r}{2}\left(t_{k}+t_{k}\right)=m c_{\max }^{c}-r \cdot t_{k}
$$

Offering a lower price might lead $k$ to win the auction if $j$ 's signal is only slightly higher than $k$ 's, and then $k$ would have to set a price that is below marginal cost.

With private values, the optimal offers can be found in a similar fashion:

$$
\begin{aligned}
& T_{k}^{p}\left[t_{k}\right]=\Pi_{A}^{*}\left[m c_{A, k}^{p}\left[t_{k}\right]\right], \\
& p_{A, k}^{p}=m c_{A, k}^{p}\left[t_{k}\right]=m c_{\max }^{p}-r \cdot t_{k} .
\end{aligned}
$$

\footnotetext{
${ }^{7}$ It is assumed that the firms compete Nash, even though with a price auction it is conceivable that the winner is a price-leader, as its price is constrained by the auction. This would then give a new bidder an extra disadvantage under substitutes and an advantage under complements (see Gal-Or, 1985). This would, hence, be a second source of advantages, but would also complicate the analysis.
} 
From these equations it is simple to calculate the expected transfer or price, as well as the expected profits and consumer surplus.

\section{Numerical example}

Now the set-up of the numerical example is introduced, which is also used in the following sections. It is important to look at an example: the analytics can show that advantages matter, but the question that remains is how much? Table 1 introduces the parameterisation. There are two cases: in the first the facilities are substitutes, in the second complements. The marginal cost on $B$ equals 5. On $A$, the marginal cost has a range of 2; and, with two new bidders, the mean of the winner's marginal cost is 5 . The signals are IID and uniformly distributed between zero and one: for $0 \leq t \leq 1$, the distribution function of signal $t$ is $F[t]=t$, and the density $f[t]=1$.

Table 1: Parameterisation of the example

\begin{tabular}{lc}
\hline Parameter & Value \\
\hline$d_{0}$ & $115 / 5$ \\
$d_{1}$ & $-4 / 15$ \\
$d_{2}$ & $-1 / 15$ (substitutes) or $1 / 15$ (complements) \\
$r$ & 2 \\
$m c_{\max }^{p}$ & $6+1 / 3$ \\
$m c_{\max }^{c}$ & 6 \\
$m c_{b}$ & 5 \\
\hline
\end{tabular}

Table 2 tabulates the expected outcome $(\mathrm{E}[x]$ gives the expectation of $x$ ) under privatevalues; Table 3 does this for common-values. The calibration results in very similar outcomes under private- and common-values; which will help signify how differently the two settings are affected by one bidder being an incumbent. The discussion of the results will be limited, as the focus is on the case with an advantaged bidder. Because the strategies are symmetric, the results are given for any bidder $i=1,2$.

In the tables, the relative efficiency of a policy is the welfare gain from the base case (when there is no supply of $A$, and $B$ has a monopolistic price) relative to the gain from going to firstbest marginal-cost pricing. Looking at absolute values can be misleading. For instance, the auctions attain a higher welfare under complements than under substitutes, but this is because consumer surplus increases in $d_{2}$ (for given number of users). Actually, relative to the firstbest, the auctions fare worse under complements. A further advantage is that the relative measure indicates how important welfare differences are: if one policy has a $10 \%$ higher welfare, this is more impressive if the first-best has an $11 \%$ higher welfare than a $100 \%$. 
Table 2: Expected outcome under private-values with two new bidders

\begin{tabular}{|c|c|c|c|c|}
\hline & \multicolumn{2}{|c|}{ Substitutes $\left(d_{2}=-1 / 15 \approx-0.067\right)$} & \multicolumn{2}{|c|}{ Complements $\left(d_{2}=1 / 15 \approx 0.067\right)$} \\
\hline & Transfer auction & Price Auction & Transfer auction & Price Auction \\
\hline $\mathrm{E}[$ Price of $A]$ & 19.29 & 5.67 & 23.52 & 5.67 \\
\hline $\mathrm{E}[$ Price of $B]$ & 19.31 & 17.58 & 23.50 & 25.75 \\
\hline Prob. $i$ wins & 0.5 & 0.5 & 0.5 & 0.5 \\
\hline E[Consumer Surplus] & 1088.5 & 2317.9 & 1097.5 & 2862.4 \\
\hline $\mathrm{E}[$ Transfer by $i]$ & 389.7 & 0 & 661.9 & 0 \\
\hline $\mathrm{E}[$ Profit for $i$ from $A]$ & 408.27 & 36.42 & 685.98 & 47.53 \\
\hline $\mathrm{E}[$ Profit from $B]$ & 816.3 & 633.4 & 1371.8 & 1722.3 \\
\hline $\mathrm{E}[$ Welfare $]$ & 2721.4 & 3024.2 & 3841.2 & 4679.7 \\
\hline Relative efficiency $^{*}$ & 0.654 & 0.825 & 0.571 & 0.781 \\
\hline
\end{tabular}

Table 3: Expected outcome under common-values with two new bidders

\begin{tabular}{lc|c|c|c}
\hline & \multicolumn{2}{c|}{ Substitutes $\left(d_{2}=-1 / 15 \approx-0.067\right)$} & \multicolumn{2}{c}{ Complements $\left(d_{2}=1 / 15 \approx 0.067\right)$} \\
& Transfer auction & Price Auction & Transfer auction & Price Auction \\
\hline E[Price of $A]$ & 19.29 & 5.33 & 23.52 & 5.33 \\
E[Price of $B$ ] & 19.29 & 17.54 & 23.52 & 25.79 \\
Prob. $i$ wins & 0.5 & 0.5 & 0.5 & 0.5 \\
E[Consumer Surplus] & 1088.5 & 2356.9 & 1097.5 & 2906.9 \\
E[Transfer by $i$ ] & 399.0 & 0 & 673.9 & 0 \\
E[Profit for $i$ from $A$ ] & 408.08 & 18.43 & 685.79 & 23.98 \\
E[Profit from $B$ ] & 816.3 & 629.2 & 1371.7 & 1729.2 \\
E[Welfare] & 2721.0 & 3022.9 & 3840.8 & 4684.0 \\
Relative efficiency & 0.654 & 0.825 & 0.571 & 0.782 \\
\hline
\end{tabular}

\section{Private-values auctions with an incumbent}

Now we turn to the case with an incumbent bidder. The new bidder bids just as before: in the transfer auction, it offers the entire profit it would make; in the price auction, it offers to set the price at its marginal cost. In the price auction, with substitutes, the incumbent is at the disadvantage: it offers a price that leads to profit on $A$, because, if it loses, this increases the new firm's price on $A$ and thereby the profit on $B$. Conversely, with complements, the incumbent offers a price that would lead to loss from $A$. With a transfer auction, the situation is less complex. Given the signals, the incumbent just has a higher value: if it wins, it is a monopolist; when it loses, a duopolist.

\section{Transfer offer of the incumbent}

The incumbent knows the bidding strategy on the new firm. With a transfer auction, it chooses a $t_{N}$ to emulate (which will be referred to as $t$ ) that maximises its expected pay-off, and therewith it chooses its transfer offer. The objective function is

$$
O_{I}=\left(\Pi_{A}^{* *}\left[t_{I}\right]+\Pi_{B}^{* *}\left[t_{I}\right]\right) F[t]-\int_{0}^{t} T_{N}[x] \cdot f[x] d x+\int_{t}^{1} \Pi_{B}^{*}[x] \cdot f[x] d x
$$

where the first term is the expected monopolistic profit from wining the auction, the second is the expected transfer paid (i.e. the expected second-highest offer conditional on the incumbent 
winning and thus $t \geq t_{N}$ ), and the third term is the expected duopolistic profit from $B$ when losing. Superscript ${ }^{* *}$ indicates a monopoly, and ${ }^{*}$ a duopoly. Differentiating (10) to $t$ gives

$$
\frac{\partial O_{I}}{\partial t}=0=\left(\Pi_{A}^{* *}\left[t_{I}\right]+\Pi_{B}^{* *}\left[t_{I}\right]-\Pi_{B}^{*}[t]\right) f[t]-T_{N}[t] \cdot f[t]
$$

where the term between brackets gives the profit gain from being a monopolist instead of a duopolist. This profit gain is larger than the profit a new bidder would make. Unless we have two independent markets, when the two profits would be equal, and thus having an incumbent has no effect. Therefore, the incumbent offers a higher transfer, and emulates a $t_{N}$ that is above its own signal.

This raises the question what the bidding will be when the incumbent always wins. If $t_{I}$ is really high, the new bidder can never out bid the incumbent, and $f[t]$ in (11) will be zero. The incumbent could then offer any transfer above $T_{N}[1]$ (the new bidder's offer when $t_{N}=1$ ). Figure 1 illustrates the bidding using the numerical example (as introduced in Section 3); the left panel does this for substitutes $\left(d_{2} \approx-0.067\right)$, and the right for complements $\left(d_{2} \approx 0.067\right)$. In the Figure, with substitutes, the incumbent always wins if $t_{I}>0.66$; and it is assumed that the incumbent offers its profit gain (which is a weekly dominant strategy, but so is any bid above $T_{N}[1]$ ). The outcome is independent of the incumbent's choice here (as long as its offer is above $T_{N}[1]$ ), as it always wins and pays the new bidder's offer.

Conversely, the outcome does depend on what happens when $t_{N}$ is so low that the new firm never wins (e.g. in Figure 1, with substitutes, when $t_{N}<0.35$ ), as then the new firm's bid determines what the incumbent will transfer. The example assumes that the new bidder still offers its profit, which is a weekly dominant strategy. If the new bidder followed a different strategy (or did not enter due to, for example, bidding costs) the expected transfer would differ, whereas welfare is unaffected if the value of revenue for the government is one (although not otherwise).

Figure 1: Offered transfer with substitutes (left) and complements (right)in the numerical example
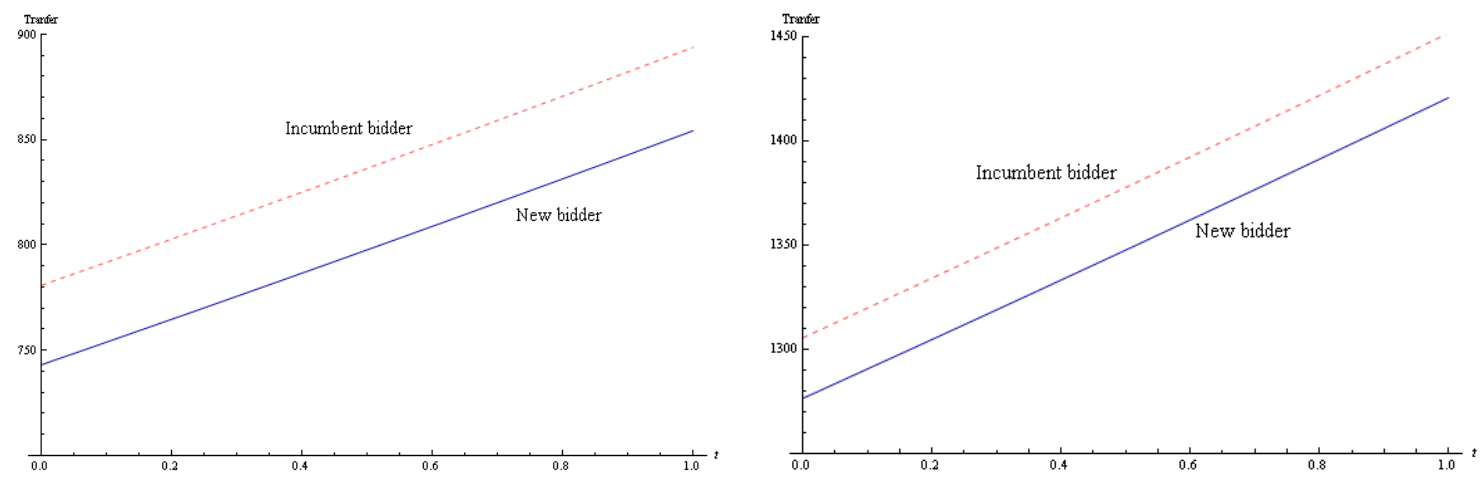

The auction is not always efficient, and the expected cost increases with the advantage. Still, because the incumbent bids more aggressively, expected revenue increases with the 
advantage. ${ }^{8}$ With complements, a duopoly's prices are higher than a monopoly's. Consequently, with an incumbent bidder, the expected mark-ups are lower than with two new bidders, and this increases welfare. With substitutes, the expected mark-ups increase in the advantage, and hence welfare tends to decrease.

\section{Price offer of the incumbent}

The objective function for the incumbent with a price auction is similar as before. The incumbent chose a $t_{N}$ to emulate; i.e. it chooses a $t$ that maximises

$$
O_{I}=\int_{0}^{t}\left(\Pi_{A}^{* *}\left[t_{I}, p_{A, N}^{p}[x]\right]+\Pi_{B}^{* *}\left[t_{I}, p_{A, N}^{p}[x]\right]\right) \cdot f[x] d x+\int_{t}^{1} \Pi_{B}^{*}\left[p_{A, N}^{p}[t]\right] \cdot f[x] d x ;
$$

where the first integral gives the expected profit from winning $A$, and the second from losing. The $p_{A, N}^{p}[t]$ is the price the new firm offers when its signal is $t .^{9}$ The f.o.c. of the incumbent's choice is

$$
\frac{\partial O_{I}}{\partial t}=0=\left(\Pi_{A}^{* *}\left[t_{I}, p_{A, N}^{p}[t]\right]+\Pi_{B}^{* *}\left[t_{I}, p_{A, N}^{p}[t]\right]-\Pi_{B}^{*}\left[p_{A, N}^{p}[t]\right]\right) f[t]+(1-F[t]) \frac{\partial \Pi_{B}^{*}}{\partial p_{A}} \frac{\partial p_{A, N}^{p}[t]}{\partial t}
$$

where the term between brackets gives the profit gain from winning $A$ when the new bidder has a signal $t$. The second term is for when the new bidder wins, and gives the increase in profit from $B$ due to a marginal increase in $t$. Condition (13) implicitly defines the optimal offer. Given the linear nature of the model, it is possible to analytically solve it; but this solution is long and not insightful. For strong substitutes, the solution can even be an imaginary number, and hence then no real solution exists.

To help explain this setting, Figure 2 illustrates bidding in a price auction using the numerical example. As noted, with substitutes, the incumbent is disadvantaged and, for given signals, offers a higher price; with complements, the incumbent is disadvantaged and offers a lower price.

Figure 2: Offered price with substitutes (left) and complements (right)
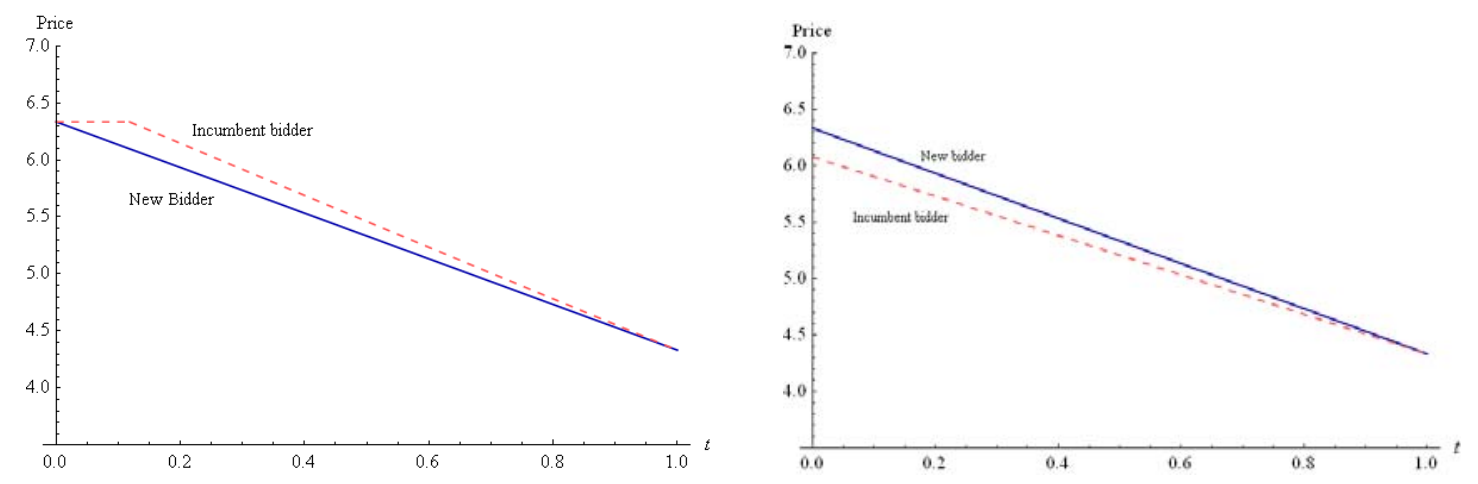

\footnotetext{
${ }^{8}$ This corresponds with the results in Burkart (1995) on the takeover of a firm under a toehold bidder.

${ }^{9}$ The profits when winning depend on the incumbent's signal $\left(t_{I}\right)$ - as this determines the marginal cost from (4) — and the loser's signal—as this determines the price. The profit on $B$ when losing $\left(\Pi_{A}^{*}\right)$ only depends on the price incumbent offered and thus on $t$.
} 
Returning to the analytics, assuming that a solution exists, with complements and given signals, the incumbent sets a lower price than the new firm: $t>t_{I}$. To show this, we start with the situation $t=t_{I}$. Then, the first term of (13) equals zero, ${ }^{10}$ whereas the second term is positive if $t_{l}<1 .{ }^{11}$ To equate the f.o.c. of (13) to zero, the $t$ has to increase. ${ }^{12}$ Although, if $t_{I}=1$, the second term in (13) is zero since $1-F[t]=0$, and the incumbent gives the same offer as the new bidder would: $p_{A, N}^{p}[1]=p_{A, I}^{p}[1]$.

Symmetrically, with substitutes, the $t$ should be smaller than $t_{I}$. At $t=t_{I}$, the first term of (13) is zero and the second is negative, because, with substitutes, the profit from $B$ increases in the price of $A$ instead of decreases as happens with complements.

For the price auction to work, the government has to set a maximum price. Otherwise the incumbent is typically better off by bidding the unregulated duopolistic price (or higher) instead nodding following (13). Thereby, it loses the auction, but gains a much better outcome for $B$, which often raises its total profit. The government has to ensure that the incumbent bids seriously. An obvious candidate for this maximum is the highest possible marginal cost, and this is also used in the example (in the example of Figure 2 this explains the horizontal section of the dashed bidding curve, as here the constraint is binding).

A slightly higher maximum price has an effect with substitutes, but not with complements. With substitutes, for the range of $t_{I}$ where the incumbent can never win (i.e. from zero to the critical value), the best it can do is offer the highest possible price. A higher reserve would thus lower welfare. But the loss might not be that large: in the numerical example, when we compare the reserve $p_{A} \leq m c_{m a c}$ with the case where the incumbent can set the duopolistic price when $t_{I}$ is below the critical value (but not when it is above it), the latter has a welfare that is $1 \%$ lower. The welfare from a realistic reserve (which ensures that the incumbent bids seriously) is in between these two cases; and thus the loss from a higher maximum might be limited. Still, the loss is larger when the range for with incumbent never wins is larger: e.g. a more negative $d_{2}$ or less heterogeneity in the marginal cost.

\section{Numerical example}

We now continue with the numerical example. As discussed Figure 1 gives the example transfer offers, and 2 the price offers. Table 4 discusses the effects of the auctions averaged over all possible signals.

In the transfer auction, the incumbent offers a higher transfer for a given signal, as when it wins it is a monopolist instead of a duopolist. The incumbent is advantaged and wins more often, but it expects to pay a higher transfer than the profit from $A$. The government gains from the higher transfer, the new bidder loses.

\footnotetext{
${ }^{10} \Pi_{A}^{* *}\left[t_{I}, p_{A, N}^{p}\left[t=t_{I}\right]\right]=0$, as the incumbent would offer a price equal to its marginal cost; and $\Pi_{B}^{* * *}\left[t_{I}, p_{A, N}^{p}\left[t=t_{I}\right]\right]=\Pi_{B}^{*}\left[p_{A, N}^{p}\left[t=t_{I}\right]\right]:$ the profit from $A$ is always zero, and thus it is always optimal for the price on $B$ to maximise the profit from $B$.

${ }^{11}$ Then $1-F[t]>0$, whereas the other two terms are negative: the profit from $B$ decreases in $A$ 's price with complements $\left(\partial \Pi_{B}^{*} / \partial p_{A}<0\right)$, and the price offer of the new bidder decreases in its signal $\left(\partial p_{A, N}^{p}[t] / \partial t<0\right)$.

${ }^{12}$ This makes the first term in (13) negative and the second term less positive (because $1-F[t]$ becomes smaller and $\partial \Pi_{B}^{*} / \partial p_{A}$ less negative).
} 
The price auction leads to a higher welfare than the transfer auction: it leads to lower expected prices and also to a slightly lower expected marginal cost. Under substitutes, even the price auction without a reserve does better than the transfer auction: it always leads to an unregulated duopoly, whereas the transfer auction leads to a monopoly $79 \%$ of the time. The price auction is also less affected by an incumbent bidder: for the price auction welfare is only slightly higher with two new bidders, whereas with the transfer auction the effect can be large. However, with a transfer auction under complements, the advantaged bidder case has a higher welfare, as it more often leads to a monopoly instead of a more harmful duopoly.

Table 4: Expected outcome under private-values

\begin{tabular}{|c|c|c|c|c|}
\hline & \multicolumn{2}{|c|}{ Substitutes $\left(d_{2}=-1 / 15 \approx-0.067\right)$} & \multicolumn{2}{|c|}{ Complements $\left(d_{2}=1 / 15 \approx 0.067\right)$} \\
\hline & Transfer auction & Price Auction & Transfer auction & Price Auction \\
\hline $\mathrm{E}[$ Price of $A]$ & 20.10 & 5.74 & 21.77 & 5.59 \\
\hline $\mathrm{E}[$ Price of $B]$ & 20.03 & 17.64 & 21.74 & 25.72 \\
\hline Prob. $N$ wins & 0.21 & 0.56 & 0.31 & 0.44 \\
\hline $\mathrm{E}[$ Marginal cost of $A]$ & 5.039 & 5.004 & 5.091 & 5.005 \\
\hline E[Consumer Surplus] & 821.1 & 2307.0 & 1273.4 & 2876.3 \\
\hline $\mathrm{E}[$ Transfer by $N]$ & 178.0 & 0 & 431.7 & 0 \\
\hline $\mathrm{E}[$ Transfer by $E]$ & 620.0 & 0 & 913.0 & 0 \\
\hline $\mathrm{E}[\text { Profit for } N \text { from } A]^{\#}$ & 178.0 & 44.6 & 431.7 & 36.5 \\
\hline $\mathrm{E}[\text { Profit for } \mathrm{E} \text { from } A]^{\#}$ & 352.3 & 36.0 & 667.9 & 46.8 \\
\hline $\mathrm{E}[$ Profit from $B]$ & 830.5 & 634.3 & 1383.5 & 1723.9 \\
\hline $\mathrm{E}[$ Welfare $]$ & 2476.1 & 3021.9 & 4040.4 & 4683.4 \\
\hline Relative efficiency $^{*}$ & 0.516 & 0.824 & 0.621 & 0.782 \\
\hline
\end{tabular}

\section{Sensitivity analysis}

This section briefly investigates how sensitive the results are to the parameterisation. It will focus on the effect of the cross-price sensitivity $\left(d_{2}\right)$. The effects of other parameters are as one would expect: for instance, a stronger sensitivity to the own-price decreases market power, and hence private supply fares better and there is less to gain from a price auction. The effect of the amount of heterogeneity in the marginal cost is also important. Less heterogeneity means that the advantaged wins even more often, as the signal difference in favour of the disadvantaged needs to be even larger for it to win. For a low amount of heterogeneity the disadvantaged bidder can never win.

As Figure 3 shows, when the facilities are stronger substitutes (more negative $d_{2}$ ) or stronger complements (more positive $d_{2}$ ), the chance that the new bidder $(N)$ wins a transfer auction decreases, as this increases the profit gain for facility $B$ from being a monopolist. Indeed, for independent markets, the incumbent is just a regular bidder; for strong substitutes $\left(d_{2}<-0.1\right)$ or complements $\left(d_{2}>0.19\right)$, the incumbent always wins. For substitutes, the relative efficiency increases with $d_{2}$, as the chance that there will be a duopoly increases. For complements, the relative efficiency also tends to increase with $d_{2}$, but now because the chance of a duopoly decreases. 
Figure 3: Sensitivity of the outcome of the transfer auction to the cross-price sensitivity $\left(d_{2}\right)$
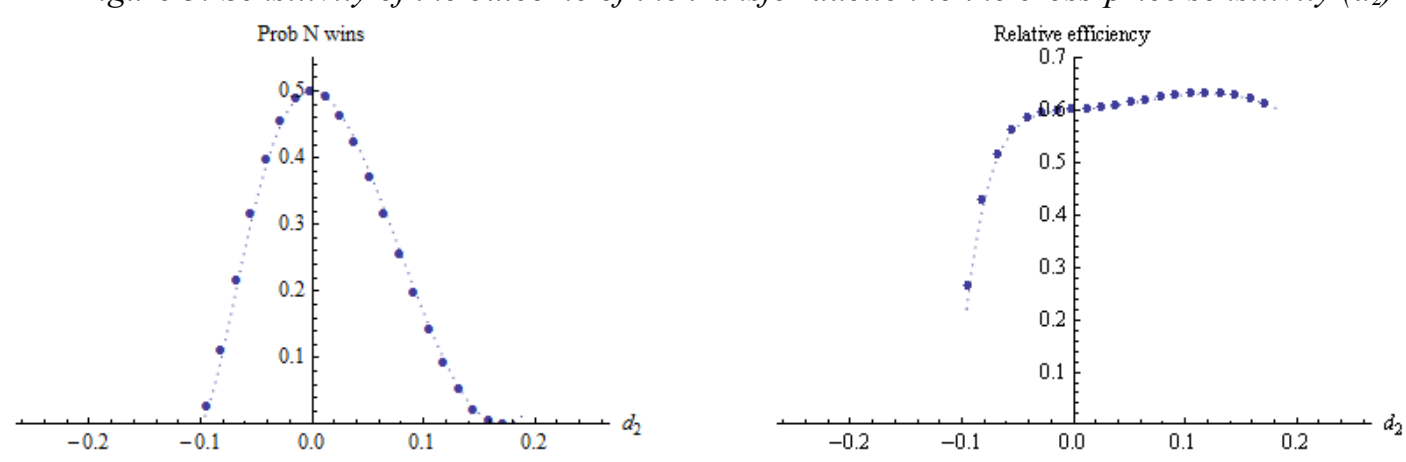

Figure 4 displays the effect of $d_{2}$ on the price auction and in particular on the chance that the new bidder wins and the relative efficiency. As discussed, with substitutes the new bidder is advantaged and hence wins more often. This harms the incumbent, but actually increases welfare by lowering the expected price.

Figure 4: Sensitivity of the outcome of the price auction to the cross-price sensitivity $\left(d_{2}\right)$

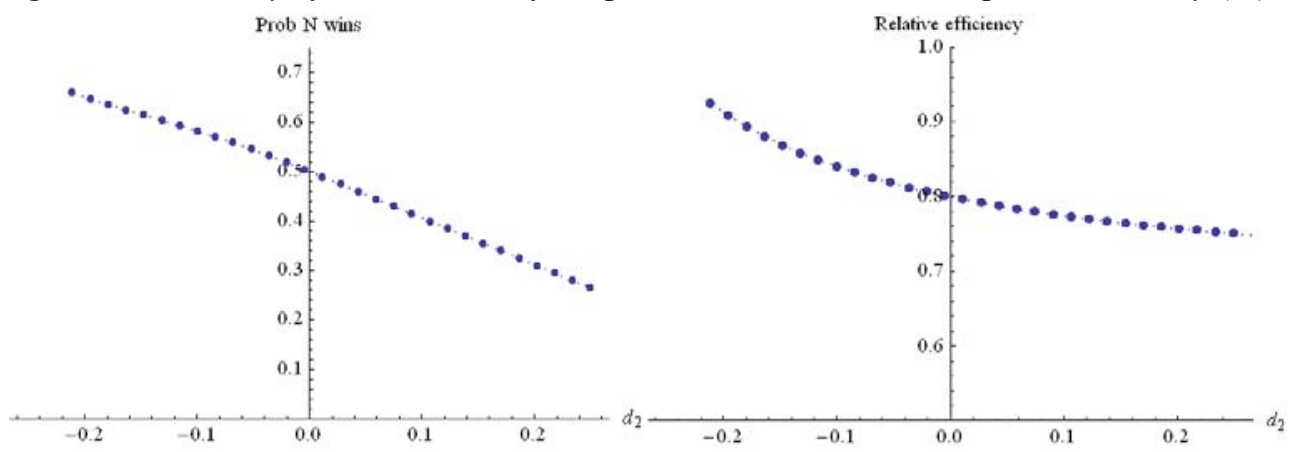

\section{Common-values auctions with an incumbent}

With common-values, the advantaged bidder always wins the auction. In a transfer auction, the incumbent is advantaged: for given signals, the new bidder can offer the duopolistic profit from $A$, the incumbent offers the expected maximum profit gain due to being a monopolist on $A$ and $B$ instead of a duopolist on $B$. The incumbent can offer the higher transfer unless the demands are independent and there are just two standard bidders. In a price auction, the advantage depends. With complements and given signals, the incumbent offers a lower price; with substitutes, it offers a higher price.

\section{Numerical example}

We now turn to the numerical example. The results in Table 5 should be compared to those in Table 3 for two new bidders. Interestingly, having an advantaged bidder that always wins needs not be bad: now, with complements, a transfer auction leads to an unregulated monopoly, whereas, in Table 3, the more harmful duopoly occurs $50 \%$ of the time. Conversely, with substitutes, the transfer auction works badly: it not only attains less revenue than without advantages, it also ensures a monopoly. 
The results assume that the new bidder still bids its value and thus offers the profit it would make under $t_{I}=0$. This may not be realistic, as the new bidder has no chance of winning, and thus, if there are the tiniest bidding costs it would never enter the auction. Then, welfare would be unchanged, as the same prices would be set, but the transfer would be zero.

Just as with private-values, in the price auction, the government imposes a maximum price equal to the highest possible marginal cost. It may not be able to set such a maximum, or the maximum may be higher. The worse possible outcome is when there is no maximum at all. Then, under substitutes, the outcomes of the price and transfer auctions are the same: both make the incumbent the unregulated monopolist. Under complements, the price auction fares better; the incumbent has 2 choices: (1) win $A$, and own both facilities with tiny profit on $A$ and a large one on $B$, or (2) be a duopolist and get a medium profit from $B$, as the new firm will set a Nash-equilibrium price that is above the monopolistic one. The incumbent will tend to be better off the former case, which also has the higher welfare. ${ }^{13}$

Table 5: Expected outcome under common-values and no reserve

\begin{tabular}{lc|c|c|c}
\hline & \multicolumn{2}{c|}{ Substitutes $\left(d_{2}=-1 / 15\right)$} & \multicolumn{2}{c}{ Complements $\left(d_{2}=-1 / 15\right)$} \\
& Transfer auction & Price Auction & Transfer auction & Price Auction \\
\hline E[Price of $A$ ] & 21.67 & 6.00 & 21.67 & 5.50 \\
E[Price of $B$ ] & 21.67 & 17.63 & 21.67 & 25.71 \\
Prob. $N$ wins & 0 & 1 & 0 & 0 \\
E[Consumer Surplus] & 833.42 & 2278.99 & 1388.97 & 2889.52 \\
E[Transfer by $N]$ & 0 & 0 & 0 & 0 \\
E[Transfer by $E]$ & 788.53 & 0 & 1335.62 & 0 \\
E[Profit for $N$ from $A]$ & 0 & 746.19 & 0 & 0 \\
E[Profit for $E$ from $A]$ & 833.50 & 0 & 1389.06 & 71.99 \\
E[Profit from $B$ ] & 833.33 & 634.32 & 1388.89 & 1725.69 \\
E[Welfare] & 2500.25 & 3025.18 & 4166.92 & 4687.20 \\
Relative efficiency & 0.53 & 0.78 & 0.65 & 0.75 \\
\hline
\end{tabular}

\section{Discussion}

Now we turn to some caveats to the research. The previous sections already discussed that the price auction needs a maximum price, and that it is important what a bidder does when it always loses. It was assumed that it bids its value. If it did not enter the auction, the transfer auction would have a lower expected transfer, and the price auction a higher price.

The discussion of the welfare effects assumes that the marginal social cost of taxation is zero and thus the value of public funds is one. If the value is higher-as the revenue is used to lower distortionary taxes - the transfer auction's revenue is more valuable and thus its welfare higher. With private-values and a transfer auction, this could also make the presence of an advantaged bidder welfare improving, as this presence increases expected transfer. ${ }^{14}$

\footnotetext{
${ }^{13}$ For the common-value, no sensitivity analysis will be presented as nothing interesting happens: the advantaged bidder always wins, and the main effect in the private-values sensitivity analysis was via the advantaged bidder's position.

${ }^{14}$ There is an extensive literature on the marginal cost of taxation, which builds on Browning (1976). He found a marginal cost of 9 to $16 \%$ of revenue. Later studies often found higher costs: e.g. Kleven and Kreiner (2006) found values between $26 \%$ for the UK and $120 \%$ for Denmark.
} 
Bidders are assumed to differ in (the expectance of) the marginal costs. They could also differ in the intercept of the demand function or the price sensitivity. The results with privatevalues would be qualitatively the same. However, if marginal costs are constant, the priceauction with common-values would be affected: all bidders would then always bid the fixed and common marginal cost as the price, and thus there would be no advantages. If marginal costs are marginally non-linear, ${ }^{15}$ then there would be an advantaged bidder that always wins.

An interesting extension of this research would be sequential auctions: e.g. that first facility $B$ would be auctioned and then $A$. In a transfer auction, bidders would be willing to offer a premium in the first auction, as winning it implies a advantage in the next.

\section{Conclusion and policy implications}

This paper finds that advantages due to one bidder being an incumbent matter substantially; and, in many settings, the advantaged bidder always wins, and does so at a low transfer in the transfer auction and a high price in the regulatory price auction. The incumbent is advantaged in the transfer auction. This may harm welfare, as the auction more often leads to a monopoly. If there is little heterogeneity in the bidders' marginal costs or the facilities are strong substitutes/complements, the new bidder has such a large disadvantage that it never wins. Conversely, with a price auction under substitutes, the new bidder is advantaged: for given signals, the incumbent sets a higher price as it also cares about the profit of the substitute. This also means that the expected price following a price auction increases in the advantage. With a price auction and complements, the incumbent is advantaged: it is willing to set a lower price, as this helps the other facility.

The question that remains is: what can the government do to improve the outcome? A solution could be to use a first-offer auction (where the winner has to match its own offer) instead of a second-offer auction. A weaker bidder has a better chance in a first-offer auction, and this can limit the effects of advantages (see Bulow et al., 1998; Waehrer, 1999). If a pure first-price auction is impossible, one could do a first-price auction followed by a second-price auction for the two highest bidders of the first round (see Klemperer, 2004).

An alternative would be a transfer auction with price regulation. If the government imposes a price cap, the incumbent loses its advantage. Alternatively, a rate of return regulation could limit the advantage, and thus its effects. Other policies that could help include imposing stricter reserves or, following McAfee and McMillan (1989), differentiating between types of bidders to increase the competition, and thus not necessarily choosing the best offer. Another alternative to stiffen the competition in the auction is giving the loser of the auction part of the spoils. For instance, in the Amsterdam auction of Goeree and Offerman (2004), the secondhighest bidder receives a sum from the auctioneer that depends on its offer.

\footnotetext{
${ }^{15} \mathrm{Or}$ if there are congestion costs (usage costs increase with the number of users) or network effects (the value of consumption for a given user increases with the number of users).
} 
An option that has received interest in the literature on toeholds in takeovers is giving the disadvantaged bidder a toehold at a discounted or zero price (e.g., Bulow et al., 1998; Rothkopf et al., 2003). Subsidising bidders is also an option in procurement (see, e.g., Cantillon, 2008). In the context of this paper, the government could offer a third facility only to non-incumbents. A further advantage of more and perhaps smaller facilities is that this fosters competition, and this can also raise welfare (see also Hazlett and Muñoz, 2009). A final option is attracting more bidders: this will make the auction more competitive, and may limit the effects of advantages.

\section{References}

Asker, J., Cantillon, E., 2010. Procurement when price and quality matter. RAND Journal of Economics 41(1), 1-34.

Branco, F., 1997. The design of multidimensional auctions. RAND Journal of Economics 28(1), 63-81.

Browning, E.K., 1976. The marginal cost of public funds. Journal of Political Economy 84(2), 283-298.

Bulow, J., Huang, M., Klemperer, P., 1999. Toeholds and Takeovers. Journal of Political Economy 107(3), 427-454.

Burkart, M., 1995. Initial shareholdings and overbidding in takeover contests. Journal of Finance 50(5), 1491-1515.

Cantillon, E., 2008. The effect of bidders' asymmetries on expected revenue in auctions. Games and Economic Behavior 62(1), $1-25$

Che, Y.-K., 1993. Design competition through multidimensional auctions. RAND Journal of Economics 24(4), 668-680.

Cramton, P., Gibbons, R., Klemperer, P., 1987. Dissolving a partnership efficiently. Econometrica 55(3), 615-32.

Economides, N., Salop, S.C., 1992. Competition and integration among complements, and network market structure. Journal of Industrial Economics 40(1), 105-123.

Engelbrecht-Wiggans, R., 1994. Auctions with price-proportional benefits to bidders. Games and Economic Behavior 6(3), $339-46$.

Flyvbjerg, B., Holm, M.K.S., Buhl, S.L., 2003. How common and how large are cost overruns in transport infrastructure projects? Transport Reviews 23(1), 71-88.

Flyvbjerg, B., Holm, M.K.S., Buhl, S.L., 2006. Inaccuracy in Traffic Forecasts. Transport Reviews 26(1), 1-24.

Gal-Or, E., 1985. First mover and second mover advantages. International Economic Review 26(3), 649-653.

Goeree, J.K., Maasland, E., Onderstal, S., Turner, J.L., 2005. How (not) to raise money. Journal of Political Economy 113(4), $897-918$.

Goeree, J.K., Offerman, T., 2004. Notes and comments the Amsterdam auction. Econometrica 72(1), 281-294.

Hazlett, T.W, Muñoz, R.E., 2009. A welfare analysis of spectrum allocation policies. RAND Journal of Economics 40(3), 424454.

Klemperer, P., 1998. Auctions with almost common values: the 'wallet game' and its applications. European Economic Review 42(3-5), 757-769.

Klemperer, P., 2004. Auctions: Theory and Practice, Princeton, NJ: Princeton University Press.

Kleven, H.J., Kreiner, C.T., 2006. The marginal cost of public funds: hours of work versus labor force participation. Journal of Public Economics 90(10-11), 1955-1973.

Krishna, V., Rosenthal, R., 1996. Simultaneous auctions with synergies. Games and Economic Behavior 17(1), 1-31.

Mas-Colell, A., Whinston, M.D., Green, J.R., 1995. Microeconomic Theory. New York: Oxford University Press.

McAfee, P.R., McMillan, J., 1989. Government procurement and international trade. Journal of International Economics 26(3-4) 291-308.

Rothkopf, M.H., Harstad, R.M., Fu , Y., 2003. Is subsidizing inefficient bidders actually costly? Management Science 49(1), 71-84.

van den Berg, V.A.C., 2012. Auctions for private congestible infrastructures. Tinbergen Institute Discussion Paper, 12-087/3.

Verhoef, E.T., 2007. Second-best road pricing through highway franchising. Journal of Urban Economics 62(2), 337-361.

Waehrer, K., 1999. Asymmetric private values auctions with application to joint bidding and mergers. International Journal of Industrial Organization 17(3), 437-452. 